\title{
Erratum to: Heart rate recovery following maximal arm and leg-ergometry
}

\author{
Sushant M. Ranadive • Christopher A. Fahs • \\ Huimin Yan • Lindy M. Rossow • \\ Stamatis Agiovlasitis • Bo Fernhall
}

Published online: 15 March 2011

(c) Springer-Verlag 2011

\section{Erratum to: Clin Auton Res}

\section{DOI 10.1007/s10286-010-0094-2}

The original version of this article unfortunately contained a mistake.

The name of the author Stamatis Agiovlasitis was spelt incorrectly.

The online version of the original article can be found under doi:10.1007/s10286-010-0094-2.

S. M. Ranadive $(\bowtie) \cdot$ C. A. Fahs · H. Yan .

L. M. Rossow - S. Agiovlasitis - B. Fernhall

Exercise and Cardiovascular Research Laboratory,

Department of Kinesiology and Community Health,

Rehabilitation Education Center, University of Illinois

at Urbana-Champaign, 1207 S. Oak St., Champaign,

IL 61820, USA

e-mail:sranad2@illinois.edu 